\title{
Historización del concepto de Salud Mental desde los aportes de Ignacio Ellacuría
}

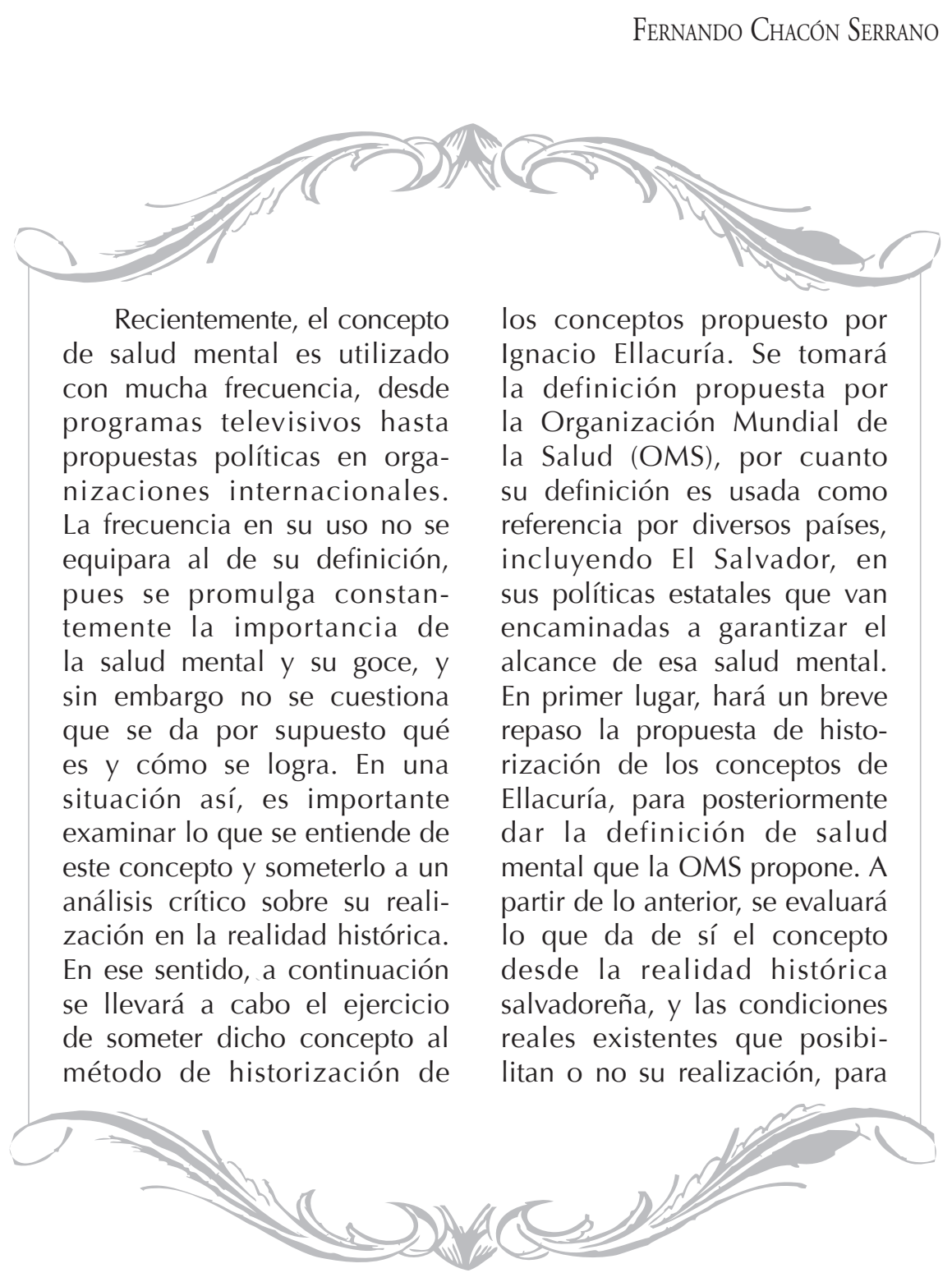


terminar haciendo uso de las categorías de denuncia y utopía que formula Ellacuría para visualizar de mejor manera las vías de realización de la salud mental.

Uno de los aportes de Ignacio Ellacuría es el método de historización de los conceptos. Este autor, propone que la historización consiste en examinar cómo se está realizando, en una situación dada, un concepto promulgado desde una visión abstracta del "deber ser"; así como también en ver la configuración de las condiciones reales que permiten que se realice el concepto tratado1. Concretamente, Ellacuría establece que la historización puede conducirse tocando los siguientes puntos: (a) la verificación práxica de la verdad-falsedad, justicia-injusticia, ajuste-desajuste del concepto promulgado; (b) la constatación de si el concepto sirve para beneficio de unos pocos y detrimento de la mayoría; (c) el examen de las condiciones reales, sin las cuales no hay posibilidad de realidad los propósitos intencionales; (d) la desideologización de los planteamientos idealistas, que se vuelven obstáculo para promover el cambio en caminado al cumplimiento del concepto; y finalmente, (e) la introducción de la dimensión tiempo para poder cuantificar y verificar cuándo las proclamaciones ideales se pueden convertir en realidades ${ }^{2}$.

Con la lupa construida a partir de las premisas anteriores, tiene que verse el concepto de salud mental. En primer lugar, debe reconocerse que dicho concepto ha evolucionado constantemente, a través de un proceso turbulento de desprendimiento del campo médico a áreas más psicológicas y sociales. Guinsberg manifiesta que se ha venido considerando la salud mental a partir de tres desviaciones claras: biologicismo, psicologicismo y sociologisismo3. En cuanto al primero, considera que la salud mental y el detrimento de la misma se deben a causas físicas meramente, sin considerar lo psicológico ni lo social. Desde ese punto, cualquier afección puede explicarse por dinámicas celulares o corticales, por ejemplo. Por otro lado, el psicologicismo pone énfasis en que la salud mental se sostiene en dinámicas psicológicas como adecuada autoestima, estabilidad emocional, etc. Por último, el sociologicismo resalta causas sociales solamente, en detrimento de lo físico y psicológico, lo que lleva a buscar explicaciones en patrones culturales, identidades sociales, o procesos de socialización alineados. Todo lo anterior, separado, sin duda refleja desviaciones en cuanto al concepto.

Lo propuesto por la Organización Mundial de la Salud (OMS) reconoce las distintas dimensiones que interactúan en la salud mental, lo que ha llevado a incluirlas en su término. Para este organismo la salud mental implica el "estado de 
completo bienestar físico, mental y social, y no solamente la ausencia de afecciones o enfermedades. Está relacionada con la promoción del bienestar, la prevención de trastornos mentales y el tratamiento y rehabilitación de las personas afectadas por dichos trastornos" 4 . La salud mental vista desde la OMS supera la visiones reduccionistas expuestas con anterioridad, lo que es positivo, por cuanto reconoce la complejidad de este término en la realidad. Rescata que no solo tiene que ver con la ausencia de enfermedad mental, sino es bienestar completo surgido a partir de la integralidad del ser humano en su área físico, psíquica y mental. Así, a simple viste, el término se muestra como adecuado, progresista, con potencial para ser utilizado por las entidades que trabajen el tema. Sin embargo, si se analiza profundamente, en su práxis histórica, lo que da de sí lo propuesto por la OMS, enmascara, con o sin intención, dificultades en su realización real. Al respecto, siguiendo a Ellacuría, es preciso preguntarse: "¿qué falla, entonces, en todo este planteamiento formalmente tan razonable y progresista para que no resulte realmente satisfactorio incluso como planteamiento?"5.

En primer lugar, la salud mental según lo ve la OMS tiene una connotación idealista y abstracta, pues en la realidad es casi imposible de conseguir un "completo bienestar" no solo en la dimensión psicológica, sino también física y social. Si evaluamos las condiciones reales en El Salvador, es claro que existe un orden social injusto que no favorece a la mayoría de población. Llegar a un "completo bienestar" puede ser posibilidad de unos pocos, quienes puedan satisfacer sus necesidades básicas de alimento, vivienda, salud; quienes tengan la opción de vivir en una zona segura, sin problemas de extorsión, delincuencia; quienes puedan acudir a asistencia médica y psicológica. Es decir, la realidad del tercer mundo no cabría en tal concepto, o más bien, el concepto no se aplicaría a dicha realidad, por cuanto se padece condiciones naturales, sociales, económicas y políticas que no garantizan el bienestar propuesto por la OMS. Por tal motivo, se podría concluir que los países del tercer mundo, entre ellos El Salvador, difícilmente están mentalmente sanos $y$, no solo eso, su orientación social, económica y política no se dirige a garantizar que se alcance lo que se quiere a nivel mental. Lo anterior, como en su momento lo denunciara Ellacuría con el bien común y los derechos humanos, requeriría, "en principio, la reestructuración de esa sociedad por el cambio radical de su ordenamiento económico (político y social)" ${ }^{\prime \prime}$.

Para especificar, si se echa una mirada a la realidad salvadoreña, se verá lo inoperante del término: por ejemplo, se padece graves 
consecuencias del cambio climático, como inundaciones y sequías, que desembocas en problemas sociales y económicos; existe una fuerte ola de violencia con 8 asesinatos diarios aproximadamente; hay poca producción, en contraposición al alza en el consumo; se acarrea con una historia dolorosa de guerra, donde todavía no existe una adecuada reparación; se sostiene una cultura machista y homofóbica, que genera más tensión social (todo lo anterior, por mencionar algunas problemáticas). Esto, sin duda, no afecta a todos por igual, ya que, aunque varios de los problemas citados se deban en buena medida a la injerencia de grupos dominantes, estos últimos poco adolecen lo expuesto. Así, pues, vale la pena preguntarse si habría un "completo bienestar" para las mayorías populares y pueblos oprimidos. Como dice Caruso: "Aceptando que una sociedad sea injusta, ¿cómo conciliar el desarrollo (completo bienestar) óptimo de los oprimidos con el de los opresores? ¿Qué es el óptimo desarrollo de un esclavo en una sociedad esclavista? ¿De una mujer en una sociedad patriarcal? Lo óptimo de los opresores se puede mantener solamente en detrimento de lo óptimo de los oprimidos y viceversa" ${ }^{\prime 7}$.

Por otro lado, las complicaciones ya expuestas sobre el goce de la salud mental acarrean consigo ciertos beneficios para algunos.
Es decir, tras lo ideal, abstracto y universal del concepto de salud mental, se oculta una realidad negadora que afecta a la mayoría y beneficia a la minoría. Concretamente, existen potencias mundiales que influyen en la configuración de condiciones desventajosas para países del tercer mundo como El Salvador. En cuanto a la salud mental, se vuelve un beneficio para estos países, como Estados Unidos, que la mayoría de población mundial no pueda gozar de este derecho, ya que existe un fuerte mercado en relación a la venta de fármacos, que genera ganancias jugosas para corporaciones transnacionales. Watters8 hace un análisis de lo que ocurre en Estados Unidos, él considera que dicho país exporta sus enfermedades mentales a nivel mundial, pues sus profesionales de la salud mental son quienes crean las categorías oficiales de las enfermedades mentales en base a una visión occidental, de primer mundo.

Lo anterior niega las dinámicas sociales, culturales e históricas propias de cada país del mundo, y obliga a las demás naciones a acoplarse a categorías como anorexia, depresión, o esquizofrenia aunque existan pensamientos, sentimientos y comportamientos propios de la cultura que no reflejan ninguna patología. Watters considera que las ganancias económicas están a la base de crear constantemente nuevas categorías de enfermedad mental, y lo ejemplifica 
con el acontecimiento de la crisis mundial, donde de inmediato aparecieron expertos advirtiendo de los daños psicológicos que traería consigo dicho fenómeno, pues "we were publicly debating, as a culture, which symptoms and pathologies we would jointly recognize as legitimate expressions of economic anxiety" ${ }^{\prime \prime}$.

A parte de las ganancias económicas que se consiguen a partir de la salud mental, también existe un objetivo importante de desenmascarar: el control social. Al definir categorías de enfermedad mental desde países dominantes, se vuelve fácil para estos determinar quiénes están mentalmente sanos y quiénes no desde sus condiciones favores. Así, a conveniencia se patologizan pensamientos y comportamientos que van en contra de lo establecido por los grupos dominantes. Es decir, aquellas personas o grupos que realicen acciones que transgredan el statu quo impuesto por grupos de poder serán etiquetadas como mentalmente insanas. A estas personas se les podrá realizar intervenciones violentas, incluso represivas, bajo el argumento de que no actúan cuerdamente. A lo largo de la historia se puede verificar este tipo de hechos.

Para ir terminando el análisis, también se vuelve preciso examinar la organización desde la que se proclama el concepto de salud mental. La Organización Mundial de la Salud es una dependencia de la Organización de las Naciones Unidas, que se encarga específicamente de cuestiones sanitarias en todo el mundo. Sobre la salud mental lleva a cabo distintas acciones como investigaciones o intervenciones, con el fin de promover ese completo bienestar en la dimensión física, mental y social en los seres humanos. Aunque las intenciones de este organismo sean verdaderas, resulta paradójico vislumbrar cómo las condiciones reales influidas por potencias mundiales imposibilitan que se cumpla eso que promulga y se esfuerza por promover. En otras palabras, la salud mental que la OMS operativiza ideal y abstractamente no se alcanzará real y concretamente siempre y cuando dentro de las Naciones Unidas existan países de primer mundo que progresan a costa de países del tercer mundo. En ese sentido, se desenmascara una hipocresía de Naciones Unidas, pues en lo formal se propone un "deber ser" que no se conseguirá nunca, si las estructuras injustas mundiales y, con especial énfasis en El Salvador, continúan. No es que quiera restársele méritos a lo positivo del concepto de salud mental de la OMS, pues reconocer la complejidad de la salud mental con su integración de distintos ámbitos es relevante. No obstante, se deja ver una utopía, el horizonte ideal del completo bienestar en lo físico, psicológico y social, pero no existe 
una denuncia de la condiciones reales existentes, ni la orientación real para construirlas. Por tanto, siguiendo a Ellacuría, vemos que "la denuncia sin utopía es, hasta cierto punto, ciega, pero la utopía sin denuncia es prácticamente inoperante, más aún, eludidora del compromiso real" 10 .

Queda claro, pues, que el concepto de salud mental que propone la OMS, deja entrever aspectos ideológicos que es preciso señalarlos. Su adopción acríticamente, ahistóricamente, favorece el sostenimiento de condiciones desventajosas para mayoría de la población, que es aquella que más sufre de dolencias físicas, mentales y sociales. Los y las profesionales de salud mental en El Salvador, poco hacen por historizar los conceptos que utilizan su trabajo, pues no se reflexiona sobre la realización de este concepto en la realidad histórica del país, y mucho menos se analiza y critica las condiciones reales que imposibilitan el goce de la salud mental. En ese sentido, falta medir la salud mental desde y para las mayorías populares, y no con categorías de las minorías; así como también, se vuelve necesario juntar utopía y denuncia, para lograr orientar la situación del estado de la salud mental en El Salvador, hacia el rumbo adecuado, no desde lo ideal, sino desde la realidad concreta de las mayorías populares.

\section{Bibliografía}

os Caruso, Igor. Psicoanálisis dialéctico. Buenos Aires: Paidós, 1964.

os Ellacuría, Ignacio. "Historización de los derechos humanos desde los pueblos oprimidos y las mayorías populares". En Lucha por la justicia: selección de textos de Ignacio Ellacuría (1969-1989), editado por Juan Antonio Senent. Bilbao: Universidad de Deusto, 2012.

os Ellacuría, Ignacio. "Historización del bien común y de los derechos humanos en una sociedad dividida". En Lucha por la justicia: selección de textos de Ignacio Ellacuría (1969-1989), editado por Juan Antonio Senent. Bilbao: Universidad de Deusto, 2012.Guinsberg, Enrique. Salud mental en el neoliberalismo. México: Plaza y Valdés, 2001.

os Organización Mundial de la Salud (OMS). Salud Mental, disponible en http://www.who.int/topics/mental_health/es/

os Watters, Ethan. Crazy like us: the globalization of the American psyche. New York: Free Press, 2010. 


\section{Notas}

1 Ignacio Ellacuría, "Historización del bien común y de los derechos humanos en una sociedad dividida", en Lucha por la justicia: selección de textos de Ignacio Ellacuria (1969-1989), Ed. Juan Antonio Senent (Bilbao: Universidad de Deusto, 2012), p. 284.

2 Ignacio Ellacuría, "Historización de los derechos humanos desde los pueblos oprimidos y las mayorías populares", en Lucha por la justicia: selección de textos de Ignacio Ellacuría (1969-1989), Ed. Juan Antonio Senent (Bilbao: Universidad de Deusto, 2012), p. 366.

3 Enrique Guinsberg, Salud mental en el neoliberalismo, (México: Plaza y Valdés, 2001), pp. 25-26.
4 Organización Mundial de la Salud (OMS), disponible en http://www.who. int/topics/mental_health/es/

5 Ellacuría, "Historización del bien común y de los derechos humanos en una sociedad dividida", p. 281.

$6 \quad$ Ibid, p. 284.

7 Igor Caruso, Psicoanálisis dialéctico, (Buenos Aires: Paidós, 1964), p. 22.

8 Ethan Watters, Crasy like us: the globalization of the American psyche, (New York: Free Press, 2010), p. 4

$9 \quad$ Ibid, p. 250

10 Ellacuría, "Historización de los derechos humanos desde los pueblos oprimidos y las mayorías populares", p. 370 . 